\title{
Polémicas e controversias sobre a gênese do escravismo
}

\author{
Vera lucia amaral Ferlini *
}

A gênese do escravismo moderno está profundamente ligada à articulação de grandes unidades produtivas, voltadas para o mercado europeu. A produção em larga escala, para um mercado distante e sem qualquer ligação imediata com o consumo, exigia grande contingente de trabalhadores que se submetessem a trabalhar para outros, sem terem, eles mesmos, qualquer motivação pelo processo de produção. E desde o final da Idade Média florescia, nas plantações de cana de açúcar do Mediterrâneo, o uso da escravidão ' ${ }^{1}$. Não se tratava de antigas formas de trabalho escravo medievais, mas de relação nova, conseqüência das transformações recentes, do capital mercantil ${ }^{2}$. Ao longo dos séculos XIV e XV cresceram os investimentos Genoveses e Venezianos na produção açucareira em Chipre, Creta e Sicilia ${ }^{3}$, incrementando o comércio mediterrâneo e estendendo suas bases à Peninsula lbérica. Granada, onde

* Profesora de la Facultad de Filosofía, Letras y Ciencias Humanas de São Paulo.

1 Jacques HeErs, Escravos e domésticos na ldade Média no Mundo Mediterrâneo, trad. port. São Paulo, Difel, 1983, p. 121-122; Charles VERLINDER, L'esclavage dans l'Europe Médieval, Bruges, «De Tempel», 1955, 2 vols.; idem, The beginnings of Modern Colonization, Ithaca, Cornell University Press, 1970; J. H. GallowaY, "The mediterranean sugar industry", Geographical Review, 67(2), 1977, p. 177-194.

2 Jacques HeERS, Escravos e domésticos, obra citada, p. 123; para DAvID BRION DAvIS, The problem of slavery in western culture, $2 .^{\text {nd }}$ ed. London, Penguin Books, 1970, p. 57, «long before the birth of Columbus, Genoese and Venetian merchants invented the distinctive instituitions that would later be applied to the African trade and West Indian colonization"».

3 Noel DEERR, The history of sugar, London, Chapman and Hall, 1919-1950, vol. II, $p$. 73-99 e Edmund von LIPPMANN, História do açúcar..., trad. port. Rio de Janeiro, IAA, 1942, 2 vols. Para Chipre consultese Charles HiLL, $A$ history of Cyprus, Cambridge, University Press, 1948. 
os genoveses tinham importante papel comércial, praticamente era una colônia italiana ${ }^{4}$. Ao mesmo tempo intensificou-se o tráfico de escravos por todo o Mediterrâneo, avançando em direção ao Atlântico. Os comerciantes de Gênova estavam também ligados ao estabelecimiento do cultivo de cana no Algarves e à produção de açúcar nas Canárias e na Madeira ${ }^{5}$. Ao mesmo tempo, a necessidade de carrear, grandes quantidades de produtos como o açúcar, a dominação da produção pelos interesses comerciais e a abertura de novas fontes de escravos na África Ocidental concorreram para a criação dessa moderna forma de trabalho ${ }^{6}$. Surgia, associada ao açúcar, uma estrutura de produção comercial, exigindo largos recursos e com base no trabalho escravo, cristalizador do complexo latifundiário monocultor ${ }^{7}$.

O desenvolvimento da produção açucareira no Algarves e nas ilhas do Atlântico foi o ponto de partida para a utilização sistemática do braço negro ${ }^{8}$. Era a constituição de nova forma de organização do trabalho, sem parâmetros na Europa, a exigir nova categoria de trabalhadores, alienados de tudo: dos meios de produção, de suas origens, de sua liberdade. O processo de produção, o destino do produto, o próprio sentido da atividade escapavam ao produtor direto.

Aparentemente, chocam-se aqui duas explicações sobre o escravismo moderno: a que atribui sua origem à necessidade de limitar o acesso à terra e a que remete a utilização do trabalho escravo à criação

\footnotetext{
4 Jacques HEERs, «Le Royaume de Granada et la politique marchand de Gênes en Occident (XV. ${ }^{\circledR}$ siécle)», Le Moyen Age, 63: 87-121, 1972; J. H. GallowaY, "The mediterranean sugar industry", obra citada, p. 192.

5 Id., Gênes au xv siécle, París, SEVPEN, 1961, p. 495-497. Para Portugal consultese VirginIa Rau E Jorge B. Macedo, O açúcar da madeira nos fins do século xv: Problemas de produçāo e comércio, Funchal, Junta Geral, 1962, p. 12-16; Francisco TENREIRO, «A ilha de São Tomé", Memórias da Junta de Investigação de Ultramar, 24: 67-74, 1961; Henrique Gomes de Amorim PARReIra, "História do Açúcar em Portugal», Anais dos Estudos da História da Geografia da Expansäo Portuguesa, Lisboa, 7: 18-70, 1952.

6 Stuart SCHWARTZ, Sugar plantations in the formation of Brazilian Society (Bahia, 1550-1835), Cambridge, University Press, 1985, p. 4-7.

7 Charles VERLINDEN, "Les influences medievales dans la colonization de l'Amerique», Revista de Historia de América, 30(2): 125-200, 1950.

8 Stuart ScHWARTZ, Sugar plantations..., obra citada, p. 6. A questão é detalhadamente discutida por Sidney Greenfield, "Madeira and the beginnings of New World sugar cane cultivation and plantation slavery: a study in institution building", in VERA RUBIN E Arthur TUDEN, Comparative perspectives on slavery in New World plantations societies, New York 1977, p. 538-552. Um estudo sumarizado aparece em Sidney GREENFIELD, “Plantations, sugar cane and slavery", Historical Reflections - Reflexions Historiques, 6(1): 85-119, 1979.
} 
de uma nova categoria de trabalhadores, dirigidos pelo capital mercantil. $\mathrm{Na}$ verdade essas abordagens não são excludentes. Senão vejamos.

A primeira explicação remete à questão da fronteira aberta, ou seja, à existência de grande abundância de terras passiveis de serem ocupadas. Nesse sentido, o escravismo impedia a apropriação e ocupação de terras por colonos povoadores (que desenvolveriam produção para o próprio consumo), direcionando a economia para o fornecimento, em larga escala e dentro do sentido mercantilista, de produtos altamente rentáveis para o comércio europeu ${ }^{9}$. Essa análise fundamenta-se nas reflexões de Marx sobre a teoria da moderna colonização ${ }^{10}$ e foi retomada por Eric Williams, para quem, nas colônias produtoras de açúcar e fumo, a «terra e o capital eram inúteis a não ser que o trabalho pudesse ser controlado", pois sem a compulsão "o trabalhador exerceria então sua inclinação natural para cuidar de sua própria terra e labutar por conta própria» " ${ }^{11}$. Em seu complexo e abrangente estudo, Fernando Novais tomou esse ângulo de explicação, considerando que «nas condições históricas em que se processa a colonização da América, a implantação de formas compulsórias de trabalho decorria fundamentalmente da necessidade de adequação da empresa colonizadora aos mecanismos do Antigo Sistema Colonial, tendente a promover a primitiva acumulação capitalista na economia européia; do contrário, dada a abundância de um fator de produção (a terra), o resultado seria a constituição no Ultramar de núcleos europeus de povoamento, desenvolvendo una economia de subsistência voltada para o seu próprio consumo» ${ }^{12}$. Barros Castro criticou severamente essas análises. Para ele, «não faz sentido falar em escassez de oferta de mão-de-obra em Portugal, e isto, independentemente de haver ou não uma grande quantidade de pobres sem terra e mesmo sem paradeiro no Reino. Por razões semelhantes, não é possível, "explicar" a escravidão nas colônias pela tese fronteira aberta - trabalho compulsório» ${ }^{13}$. Assim, é artificioso tal raciocínio, na medida em que, (sic) teria por base a alternativa do trabalho assalariado, pois o «trabalho escravo

\footnotetext{
9 Fernando A. Novals, Portugal e Brasil na crise do antigo Sistema Colonial (17771808), São Paulo, Hucitec, 1979, p. 102.

10 Karl MARX, "Teoria Moderna da Colonização", O Capital, trad. port., 2." ed. Rio de Janeiro, Civilizaçāo Brasileira, 1971, Livro 1, vol. II, p. 893.

11 Eric Williams, Capitalismo e escravidāo, trad. port., Rio de Janeiro, Editora Americana, 1975, p. 8-9.

12 Fernando A. Novals, Portugal e Brasil na crise..., obra citada, p. 102.

13 Antonio BARROS DE CASTRO, Escravos e senhores nos engenhos do Brasil. Um estudo sobre os trabalhos do Açúcar e a politica económica dos Senhores, São Paulo, Unicamp, tese de doutoramento, 1976, p. 25-26.
} 
é requerido (...) por uma engrenagem que deve ser entendida a partir da análise do processo de trabalho escravo, e das condições impostas pela competição intercolonial. Em outras palavras, na cadeia dos provedores de mercadorias coloniais, o cativo não constitui uma "alternativa" para o trabalho livre: o escravo é ali "socialmente necessário"» ${ }^{14}$. Ou seja, "0 escravismo é, no engenho, um recurso ao mais primitivo para viabilizar o mais moderno, e o escravo de engenho, não obstante a brutal primazia da relação relação homem (senhor, feitor) a homem (cativo); é um atalho em direção ao moderno proletário" ${ }^{15}$.

Chegamos aqui ao cerne da segunda vertente de explicações: o escravismo como forma possivel e adequada à constituição, nas colônias, de mão-de-obra para o capital. Em suma, o processo de proletarização na Europa e o desenvolvimento do escravismo nas colônias, «representaram formas peculiares de organização social do trabalho para a obtenção, sob garantia absoluta, do lucro capitalista, e ambas se configuram pela concentração em um mesmo lugar de trabalho, e em larga escala, de trabalhadores despossuídos de meios de produção e de saber técnico" ${ }^{16}$.

Sem tocarmos, por enquanto, nas vinculações que os autores partidários dessa corrente fazem entre escravismo colonial e capitalismo, retomemos a possivel contradição entre as duas explicações.

Para Maria Sylvia de Carvalho Franco, o «recurso ao trabalho escravo poderia ser explicado com o argumento de que, na colônia, sería impossivel a preservação de homens livres, na condição de expropriados, dada a abundância de terras, onde todos poderiam encontrar meios de se auto-suprirem. Convém lembrar, entretanto, que o entrosamento entre produção colonial e comércio capitalista, que levou à organização das grandes propriedades fundiárias, ocorreu numa época em que jamais poderiam ter sido utilizados homens livres, pela muito simples e muito forte razão de que o sujeito expropriado dos meios de produção e obrigado a vender sua força de trabalho não existia como categoria social, capaz de

14 Antonio BARRos de CASTro, "As mãos e os pés do senhor de engenho", in Paulo Sérgio Pinheiro (org.), Trabalho escravo, economia e sociedade, Rio de Janeiro, Paz e Terra, 1984, p. 50.

15 Idem, Escravos e senhores nos engenhos do Brasil, obra citada, p. 39.

16 Edgar DE DECcA, O nascimento das fábricas, Sāo Paulo, Brasiliense, 1982, p. 47. 
preencher as necessidades de mão-de-obra requeridas pela produção colonial» ${ }^{17}$.

Ora, realmente a existência de ampla oferta de terras, no início da colonização, nada significaria sem os recursos materiais para a implantação da produção açucareira e, principalmente, sem braços. Pensar-se que, no século XVI, a alocação de colonos brancos no Brasil poderia levar à produção de subsistência parece artificialismo, na medida em que chamamos mesmo a atenção para as dificuldades da Coroa em carrear portugueses para a fixação. Todavia, a preocupação da Coroa era trazer brancos associados ao açúcar, à dinâmica de uma produção mercantil e não, simplesmente, ao esforço de uma política de povoamento. A vinculação inicial da doação de terras à produção açucareira determinava, de antemão, o tipo de colonização e o papel do branco, pois a produção do açúcar era "naturalmente» entendida como labor de escravos. Para esse tipo de trabalho não se concebia, realmente, à época, a atividade de um homem livre ${ }^{18}$.

Exatamente essa historicidade da mão-de-obra nas colônias, no contexto do capital comercial, embasa as explicações de Eric Williams e Fernando Novais.

Para o primeiro, quando «a escravidão é adotada, não é adotada como uma escolha em detrimento do trabalho livre; não há qualquer escolha " ${ }^{19}$. E embora continue sua análise com base na carência demográfica européia, conclui que não havia no século XVI os trabalhadores-livres necessários para cultivar cana-de-açúcar, tabaco e algodão no Novo Mundo. Isto é, remete à situação específica da época: «a escravidão negra, portanto, era apenas uma solução, em certas circunstâncias históricas do problema de mão-de-obra das Antilhas ${ }^{20}$.

Novais, por sua vez, pondera que, embora examinemos analiticamente a impossibilidade dessas alternativas, aos homens do início dos

17 Maria Sylvia de CaRvalho Franco, «Organização social do trabalho no período colonial», in Paulo Sérgio Pinheiro (org.), Trabalho escravo, economia e sociedade, obra citada, p. 178.

${ }_{18}$ Para o Padre Fernão Cardim o serviço dos engenhos "é insofrível, sempre os serventes andam correndo, e por isso morrem muitos escravos...", Tratado da terra e da gente do Brasil (1583-1590), 3. ${ }^{\mathrm{a}}$ ed. São Paulo, Nacional/Mec, 1970, p. 193.

19 Eric Williams, Capitalismo e escravidão, obra citada, p. 10.

20 Idem, ibídem, p. 56. 
Tempos Modernos, que montaram a colonização , a produção escravista (ou para-escravista) devia apresentar-se, como observou Eric Williams, quase como «natural» tal o condiciona mento histórico-econômico em que se movia a expansão européia ${ }^{21}$.

Retomando o percurso histórico da produção de açúcar na Época Moderna, percebe-se como o escravismo desenvolveu-se inextricavelmente ligado ao complexo açucareiro mercantil. $E$ a restrição à ocupação indiscriminada das terras já estava dada pela produção açucareira, entendida apenas como escravista. Produzir com escravos era produzir mais, em grandes propriedades, excluindo os pequenos produtores. Era incentivar produção em escala. Associar-se a ela, na colônia, mesmo como lavradores de cana, correspondia a dirigir o trabalho dos escravos, a ter escravos $^{22}$. E se é certo, portanto, ser a restrição às terras, por assim dizer, estrutural, era pelo escravismo que ela se dava. Pois, como base da produção açucareira (e depois, de outras culturas de exportação) correspondia à dinâmica do capital mercantil, a criar essa forma de produção para garantir a realização de seu lucro. De outra maneira não poderemos entender porque, como acentuam Heers o Verlinden, ter o escravismo moderno surgido justamente nas culturas novas, ligadas às atividades mercantis de larga escala ${ }^{23}$. E a semelhança da organização da produção açucareira às formas de organização manufatureiras européias não é simples coincidência. Correspondem ambas à racionalidade do capital mercantil, dentro de possibilidades historicamente dadas.

Mas a organização de produção em unidades centralizadas não objetivava simplesmente a produção em larga escala. Esta poderia ser obtida pela agregação final da produção de pequenas unidades. Correspondia, sim, à necessidade de controle da produção pelo capital mercantil, que não mais se satisfazia em comercializar os frutos dispersos, mas se interessava em garantir para si, realmente, o monopólio da maior quantidade de produtos. Dessa forma, a nova organização produ-

21 Fernando A. Novals, Portugal e Brasil..., obra citada, p. 103.

22 No início do século XVIi, o cronista ressaltava: «E todos, assim uns como outros, fazem suas lavouras e granjearias com escravos de Guiné, que para esse efeito compram por subido preço. E com os tais escravos não lhes sofre o ânimo ocupar a nenhum deles em cousas que não seja tocante à lavoura que professam, de maneira que têm por tempo perdido o que gastam em plantas uma árvore, que lhes haja de dar fruto em dois ou três anos, por lhes parecer que é muita demora” (Diálogo das Grandezas do Brasil (1618), 2 . $^{\text {a }}$ ed. Recife, Imprensa Universitária, 1966, p. 10).

23 Jacques HeERS, Escravos e domésticos..., obra citada, p. 122; Charles VERLINDEN, L'esclavage dans l'Europe medieval, obra citada, p. 632. 
tiva deveria tanto restringir a possibilidade da produção dispersa, como constituir forma de trabalho compativel com seu sentido mercantil. Essa forma era, porém, incompatível com os padrões vigentes na Europa, apresentando-se como desumana, insofrivel por seres humanos ${ }^{24}$.

Há pois dois movimentos a apreender no processo de constituição da moderna produção mercantil escravista. De um lado, a centralização e a concentração da produção, dirigidas pelo capital mercantil e que pressupunham o monopólio de terras para suas determinaçōes. De outro, mas no mesmo processo de constituição da moderna produção mercantil, essa concentração exigia ponderável número de um tipo específco de trabalhadores, o que só era possível, naquela época, pela compulsão.

Surgindo em seu sentido mercantil juntamente com o processo de acumulação de capitais, a produção de açúcar aparecia como «naturalmente" possivel apenas em grande escala, carecendo de braço escravo e de largas porções de terra. O capital mercantil ao dedicar-se à produção açucareira estruturou-a sob a forma de grande exploração, o que requereu a adoção de uma forma de trabalho específica: o trabalho escravo, capaz de impedir a exploração desse ramo de negócio por pequenos produtores. O sentido mesmo da necessidade de escravos estava na “racionalização» extensiva da produção. Produzir com escravos era produzir mais, excluincio os produtores não escravistas: a produção escravista em larga escala dependia de grandes extensões de terra para sua expansão, que requeria mais e mais escravos.

No caso do Brasil a escolha do açúcar como produção para garantir a ocupação continha, em sí, a dinâmica do capital mercantil específica dessa produção e pressupunha escravismo e grande propriedade, excluindo, praticamente a priori, a pequena produção. Como afirmava Van der Dussen analisando as condições de ocupação do Brasil:

«assim os que pretendem fixar-se no país devem trazer alguns bens e, para serem bem sucedidos devem comprar alguns negros, porque sem negros nada se pode cultivar aqui, e nenhum branco - por mais disposto ao trabalho que tenha sido na Pátria - se pode dedicar no Brasil a trabalhos tais, nem mesmo consegue suportá-lo... ${ }^{25}$.

24 Cf. Tratado da terra e gente do Brasil (1583-1590), obra citada, p. 193.

25 Adriaen VAN DER DUSSEN, Relatório sobre as capitanias conquistadas (1639) suas condições econômicas e sociais, trad. de José Antonio Gonsalves de Mello, Rio de Janeiro, Instituto do Açúcar e do Álcool, 1947, p. 85. 
Se partirmos do pressuposto que a estruturação latifundiária e escravista do açúcar obedecia à necessidade de maximalização dos lucros imposta pelo capital mercantil, não haverá contradição entre as explicações. Foi realmente necessário criar nova forma de trabalhador, trabalhando para o capital mercantil e não para si mesmos, garantindo a utilização da terra para o capital e para a produção externalizada. E a objeção colocada por Castro à teoria da fronteira aberta não se mantém. É certo ter o escravismo se imposto inexoravelmente em certas regiões e em outras não haver deitado raizes ${ }^{26}$. Mas é certo também que onde o escravismo se impôs, a apropriação de terras para outros fins e com outra forma de trabalho não era possivel e o colono branco esteve vinculado às determinações da produção mercantil e escravista. Essa situação, clara aos homens da época, aparece no relatório holandês de 1639, ao estabelecer, dentre as espécies de homens a povoar o Brasil, ser a primeira,

«a dos que trazem dinheiro da Pátria, isto é, os que são negociantes ou empregados deles e que aqui têm prosperado, compram engenhos, partidos de cana...." ${ }^{27}$.

Não há, portanto, disparidade nas explicações, no limite, complementares. A racionalidade do capital mercantil, geratriz do escravismo enquanto trabalho alienado, criava, na mesma dinâmica, impecilhos para o aproveitamento da terra fora de suas determinaçōes. O fato de não haver ocorrido a tendência à pequena propriedade de subsistência no período colonial não anula a explicação . Ao contrário, reforça-a. Quando Brandônio e Frei Vicente do Salvador queixavam-se de não haver mantimentos no Brasil e Gandavo referia-se ser ter escravos tudo que desejavam os colonos, estavam demonstrando a prévia subordinação do colono à produção exportadora e escravista ${ }^{28}$.

26 Castro afirma que a falha da teoria da fronteira aberta se coloca pela diversidade da adoção do trabalho escravo: "a escravidão se impunha inexoravelmente em certas regiões, enquanto não lograva criar raizes em outra; o escravo era necessário em Pernambuco, mas não o era no sertão. Há, pois, algo de específico que não é captado pelo argumento da fronteira aberta". ("As mãos e os pés do senhor de engenho", obra citada, p. 50.)

27 Adriaen VAN DER DUSSEN, obra citada, p. 85.

28 Diálogos das Grandezas do Brasil, obra citada, p. 10; Frei Vicente do SALVADOR, História do Brasil (1628), 3. ${ }^{a}$ ed. São Paulo, Melhoramentos, 1931; Pero dE MAGALHĀES GANDAVo, obra citada, p. 93. 
Assim, tanto a crítica feita por Castro à explicação do escravismo a partir da abundância de terras, como a contraposição da gênese do escravo como trabalhador para o capital mercantil, pecam por unilateralidade. Por outro lado, considerar o escravo das colônias atalho ao moderno proletariado implica em grave simplificação. É possivel, plenamente, aceitar-se a relação entre movimentos de constituição do proletariado na Europa e de utilização do trabalho escravo nas colônias, dentro do processo de acumulação originária de capitais ${ }^{29}$. Entretanto há que se considerar a historicidade geral da época a distinguir as trajetórias diversas, pois enquanto na Europa completou-se a proletarização, nas colônias o escravismo permaneceu como barreira ao capitalismo ${ }^{30}$. Os autores em questão tendem, todavia, a reduzir o sistema colonial, desde seu início, a mero paralelismo como o desenvolvimento capitalista, esquecendo a relação essencial, mas contraditória, entre as colônias modernas e o capital.

Os trabalhos de Castro, M. Sylvia de Carvalho Franco e Edgard de Decca têm porém, entre outros, o mérito de recuperar a questão da historicidade da divisão do trabalho, sua relação com as estruturas de poder, a constituição dos códigos disciplinares e do padrão técnico. Entretanto, o estudo detalhado dessa questões ressalta exatamente a distinção entre o escravismo moderno e o capitalismo, ao demonstrar estar a dinâmica da acumulação primitiva de capitais presente dentro das próprias relações de trabalho e da constituição social da colônia.

É preciso, então, ir mais além, pois o sistema colonial e, conseqüentemente, o escravismo estiveram inseridos em situação histórica complexa. Cumpre entendê-los não apenas nas determinações gerais do processo de acumulação, mas na criação do Brasil enquanto colônia de Portugal, em cuja constituição sobrelevou o papel do Estado. Pois o senhor de escravos o era enquanto parte do grande negócio colonial metro-

29 Fernando Novais já assinalava: «Assim, enquanto na Europa moderna o desenvolvimento capitalista "livertava" produtores diretos da servidão medieval e integrava-os como assalariados na nova estrutura de produção que destarte camuflava a exploração do trabalho, as economias coloniais periféricas montadas exatamente como alavancas do crescimento do capitalismo e integradas nas suas linhas de força, punham a nu essa mesma exploração na sua crueza mais negra... As colônias timbravam em revelar as entranhas da Europa". (Portugal e Brasil..., obra citada, p. 101-102.)

30 Maria Sylvia de Carvalho Franco expōe magnificamente como essa estrutura colonial escravista barrou a proletarização do homem livre, permitindo sua sobrevivéncia nas franjas do sistema. (Homens livres na ordem escravocrata, São Paulo, Ática, 1974, p. 1314.) 
politano: um vassalo, um agente da Coroa que arcava, "embora com alguns privilégios ou vantagens e, por vezes, com algum suporte oficial, com a construção do Império na Colônia» ${ }^{31}$. E se o escravismo levava à concentração de terras e rendas na dinâmica do capital mercantil, essa mesma concentração de terras com base no trabalho escravo permitia a transferência da ordem social estamental portuguesa: «as concessões de sesmarias demarcavam as estruturas de poder que não podiam nem deviam ser destruídas" ${ }^{32}$. Em resumo o escravismo e a concentração de terras excluíram, "ab initio, a massa da população livre, pertencente ou não à ordem estamental, da posse da terra e, por aí, do controle do poder local e do direito de ter vínculos diretos com o Estado. Em si mesmo, a terra não era uma riqueza e iria demorar algum tempo para que ela assumisse esse significado (mesmo como conexão do capital mercantil) mas erigia-se na base material da transferência e da perpetuação de uma arraigada estrutura de privilégios» ${ }^{33}$.

\footnotetext{
31 Florestan Fernandes, Circuito Fechado, São Paulo, Hucitec, 1976, p. 34.

Idem, ibídem, p. 35.

33 Idem, ibidem, p. 35.
} 